\title{
Carbon-Based Frustrated Lewis Pairs
}

\author{
Shabana Khan and Manuel Alcarazo
}

\begin{abstract}
The use of FLPs offers a new and versatile strategy to activate small molecules such as $\mathrm{H}_{2}, \mathrm{CO}_{2}$, acetylenes, disulfides, olefins, and nitrogen oxides. This chapter describes the recent advances reported on the design and reactivity of new frustrated systems constituted by at least one carbon-based partner.
\end{abstract}

Keywords Carbene $\bullet$ Ylide $•$ Allene $\bullet$ NQO1 $・$ Enamine $・$ Disulfides

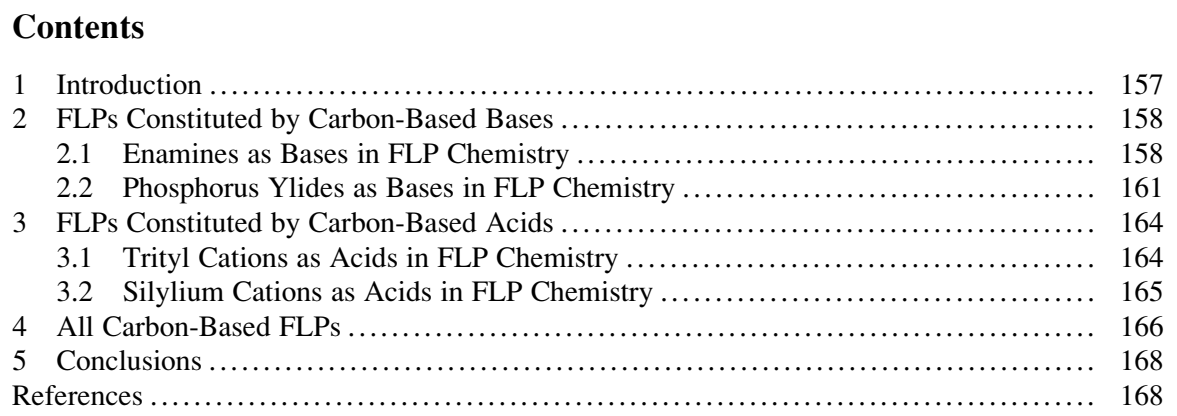

\section{Introduction}

The extension of the FLP concept to include currently unexplored partners is desirable as it may lead to the discovery of a range of interesting new applications. If we focus our attention on carbon-based FLPs it seems logical to divide them into

\footnotetext{
S. Khan and M. Alcarazo ( $\square)$

Max Planck Institut für Kohlenforschung, Kaiser Wilhelm Platz 1, 45470 Mülheim an der Ruhr, Germany

e-mail: alcarazo@mpi-muelheim.mpg.de
} 


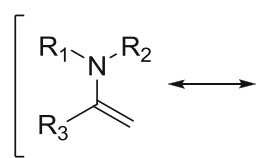

A

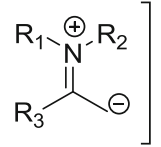

$A^{\prime}$

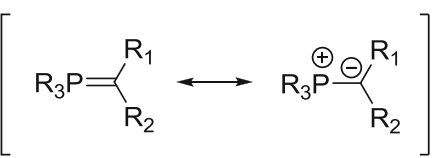

B
B'

Scheme 1 Resonance forms of enamines and phosphorus ylides

three different groups depending on the nature of the base and acid involved: (1) FLPs in which only the base is carbogenic, (2) FLPs containing a carbon-based acid, and (3) FLPs in which both partners are carbon-based. Probably the most obvious carbon-based bases for this chemistry are $\mathrm{N}$-heterocyclic carbenes (NHCs) due to their strong basicity combined with the easy modulation of their stereoelectronic properties. The advances in this particular field are reviewed in the earlier chapter by $\mathrm{M}$. Tamm. However, other carbon-based bases such as enamines or ylides have also been applied in this area and are depicted in Sect. 2 of this chapter. Studies involving FLPs in which only the acidic partner has a carbogenic nature are quite scarce, the work of Stephan with tritylium cations probably being the most prominent example. These results are shown in Sect. 3. Finally, the last section of this chapter will be devoted to those systems in which both partners are carbon-based. Up to now these FLPs are constituted by a bulky NHC acting as a base in concurrence with an electron poor allene that behaves as a carbon-based neutral surrogate of $\mathrm{B}\left(\mathrm{C}_{6} \mathrm{~F}_{5}\right)_{3}$.

\section{FLPs Constituted by Carbon-Based Bases}

Not counting NHCs, the two main carbogenic neutral bases employed in this chemistry are enamines and ylides. The basicity at the carbon atom in both compounds can be explained by considering their resonance structures $\mathbf{A}^{\prime}$ and $\mathbf{B}^{\prime}$ that disclose a formal negative charge located at that position (Scheme 1). Due to the enhanced ability of a $\mathrm{PR}_{3}$ moiety to stabilize a positive charge, phosphorus ylides are stronger bases than enamines and therefore their range of application in FLP chemistry should be broader.

\subsection{Enamines as Bases in FLP Chemistry}

In 2002, Piers et al. synthesized a series of adducts from the reactions of $N$-benzyl imines $\mathrm{Ph}(\mathrm{R}) \mathrm{C}=\mathrm{NBn}(\mathrm{R}=\mathrm{Me}(\mathbf{1}), \mathrm{Ph}(2))$ and $t \mathrm{Bu}\left(\mathrm{CH}_{3}\right) \mathrm{C}=\mathrm{NBn}$ (3) with $\mathrm{B}\left(\mathrm{C}_{6} \mathrm{~F}_{5}\right)_{3}$ [1]. Compounds 1 and 2 reacted with $\mathrm{B}\left(\mathrm{C}_{6} \mathrm{~F}_{5}\right)_{3}$ through the $\mathrm{N}$ atom affording the expected adducts; however the reaction of $\mathbf{3}$ proceeds via its enamine tautomer to form an $\alpha$-C bound adduct, 6 (Scheme 2). The formation of $\mathbf{6}$ is 


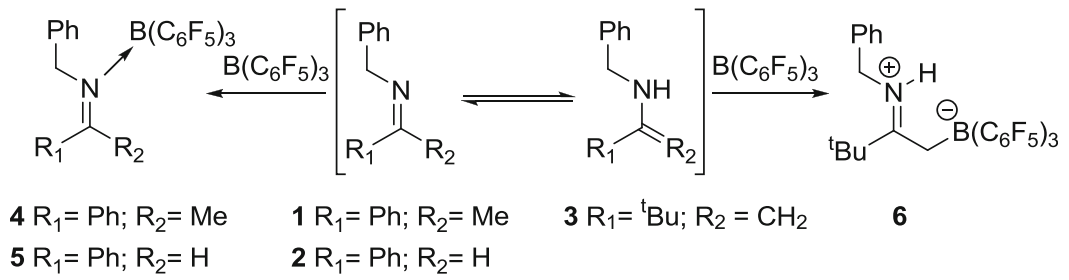

Scheme 2 Divergent reactivity of imines towards $\mathrm{B}\left(\mathrm{C}_{6} \mathrm{~F}_{5}\right)_{3}$<smiles>C1=C(N2CCOCC2)CCCC1</smiles>

7

(1)

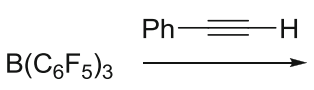

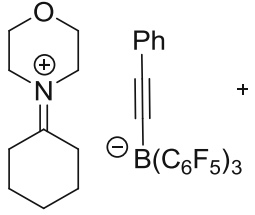

8

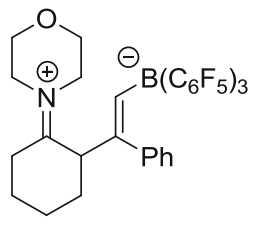

9

Scheme 3 Activation of phenylacetylene by an enamine/borane FLP

presumably due to the steric bulkiness of the $t \mathrm{Bu}$ group which cannot accommodate either the borane or the benzyl group in a syn orientation. Thus the borane traps the imine as its enamine tautomer. The formation of $\mathbf{6}$ was also corroborated by a single crystal X-ray diffraction study which shows that the B-C bond length in $\mathbf{6}$ (1.715 (2) $\AA$ ) is comparatively longer than those of other B-C bonds [2]. This is consistent with the fact that, in solution, $\mathbf{6}$ is a weak adduct whose formation has been driven probably by the presence of excess of $\mathrm{B}\left(\mathrm{C}_{6} \mathrm{~F}_{5}\right)_{3}$.

Influenced by this result and the fact that 1-morpholinocyclohexene 7 can be hydrogenated in the presence of FLPs [3], implying that the binding of $\mathrm{B}\left(\mathrm{C}_{6} \mathrm{~F}_{5}\right)_{3}$ with the enamine is weak, Stephan screened the ability of the pair $7 / B\left(\mathrm{C}_{6} \mathrm{~F}_{5}\right)_{3}$ to activate alkynes. Thus, when phenylacetylene was added to a solution of this pair, a mixture of compounds $\mathbf{8}$ and $\mathbf{9}$ was obtained involving the deprotonation of the alkyne and the addition of the FLP to the C-C triple bond respectively (Scheme 3) [4].

Electron-rich aromatic rings such as pyrroles also show the same type of reactivity as can be deduced by the resonance structures $\mathbf{1 0 a - c . ~ H e n c e , ~ w h e n ~ p y r r o l e ~ a n d ~}$ $N$-methylpyrrole were employed as bases for the activation of phenylacetylene, mixtures of 11/12 and 13/14, were obtained from the addition to positions 2 and 3 of the ring, respectively. Only the much more sterically hindered $N$-tert-butylpyrrole provided a single product 15 by substitution exclusively at position 3 (Scheme 4) [4].

Interestingly, storing a $\mathrm{CH}_{2} \mathrm{Cl}_{2}$ solution of 15 for $24 \mathrm{~h}$ led to the complete conversion to a new species, $t \mathrm{BuNC}_{4} \mathrm{H}_{4}\left(3-\mathrm{PhC}=\mathrm{C}(\mathrm{H})\left(\mathrm{C}_{6} \mathrm{~F}_{5}\right) \mathrm{B}\left(\mathrm{C}_{6} \mathrm{~F}_{5}\right)_{2}\right)(\mathbf{1 6})$, which exhibits a resonance at only $-6.8 \mathrm{ppm}$ in the ${ }^{11} \mathrm{~B}$ NMR spectrum instead of that at $-16.2 \mathrm{ppm}$ for 15. Additionally, ${ }^{19} \mathrm{~F}$ NMR spectroscopy indicated the presence of three $\mathrm{C}_{6} \mathrm{~F}_{5}$ rings which are no more equivalent. Ultimately, X-ray study on $\mathbf{1 6}$ allowed the elucidation of its structure as a bicyclic system containing a borate and an iminium moiety (Scheme 5). 


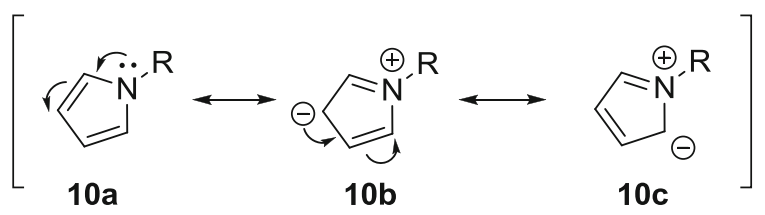

$\mathrm{PhCCH} \downarrow \mathrm{B}\left(\mathrm{C}_{6} \mathrm{~F}_{5}\right)_{3}$

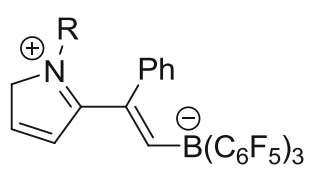

$11 \mathrm{R}=\mathrm{H}$

$13 \mathrm{R}=\mathrm{Me}$

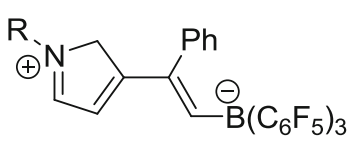

$12 \mathrm{R}=\mathrm{H}$

$14 \mathrm{R}=\mathrm{Me}$

$15 \mathrm{R}={ }^{\mathrm{t}} \mathrm{Bu}$

Scheme 4 Activation of phenylacetylene by pyrrole/borane FLPs

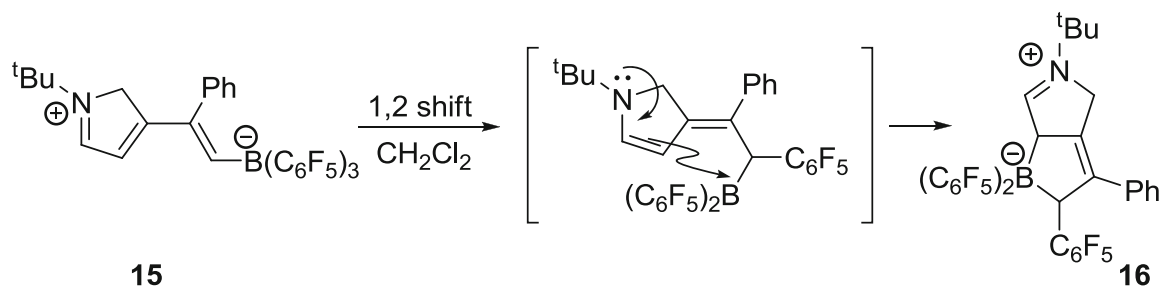

Scheme 5 Rearrangement of iminio-borates by $1,2-\mathrm{C}_{6} \mathrm{~F}_{5}$ migration

The formation of these rearranged products seems to take place via a 1,2migration of one of the $\mathrm{C}_{6} \mathrm{~F}_{5}$ groups from the boron atom to the adjacent carbon atom followed by nucleophilic attack of the thus generated enamine to the borane fragment. Such types of boron to carbon $\mathrm{C}_{6} \mathrm{~F}_{5}-1,2$-migrations are well known and constitute an important feature of this chemistry [5, 6].

Dimethylaminopentafulvenes such as $\mathbf{1 7}$ are another type of enamines with really unique structural features that have also found application as Lewis bases in FLP chemistry [7]. Again the plausible resonance structures are quite informative in explaining the observed reactivity (Scheme 6).

The reaction of alkynes with 17 /borane mixtures seems to be very sensitive to temperature. While at low temperature the kinetic product derived from addition at the position 2 of the fulvene is the only adduct isolated 18, at r.t., the attack at position 3 of the fulvene is favored, affording the bicyclic iminio-borate zwitterion 19 as thermodynamic product of this reaction (Scheme 7). 


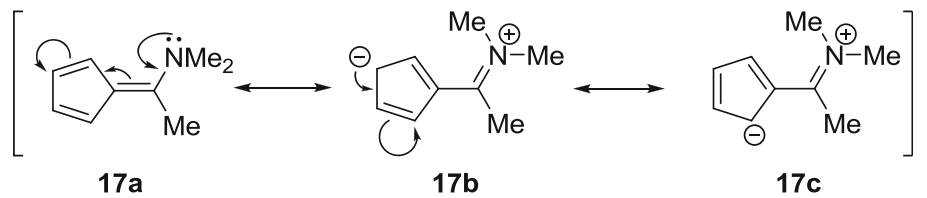

Scheme 6 Resonance structures of dimetylaminopentafulvenes

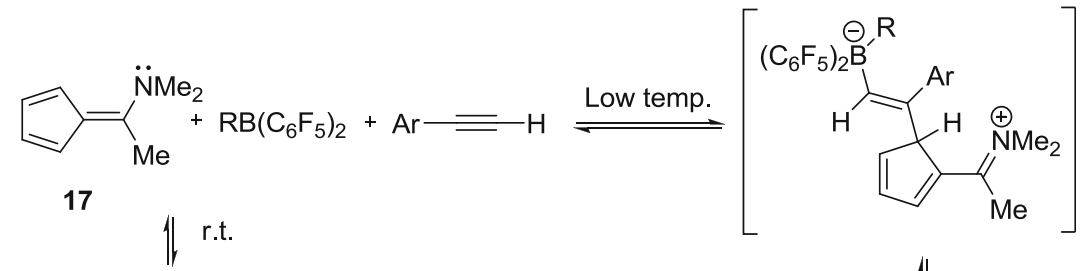

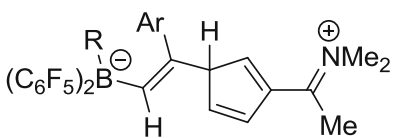<smiles>CCCC(C)C</smiles>

1) $1,5-\mathrm{H}$ shift

2) $1,2-\mathrm{R}$ shift

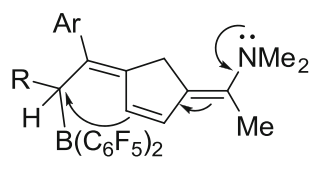

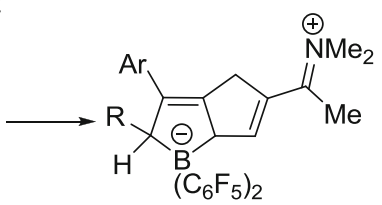

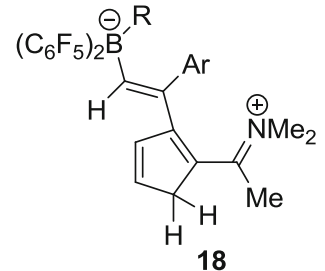

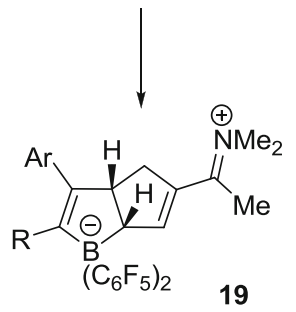

Scheme 7 Activation of alkynes by aminofulvene/borane mixtures

\subsection{Phosphorus Ylides as Bases in FLP Chemistry}

It has already been mentioned that phosphorus ylides are stronger bases than enamines and therefore, if conveniently protected by bulky groups, they should form FLPs able to activate a wider range of substrates and not only alkynes as in the case of enamines. Unfortunately, there are not many reports on the use of phosphorus ylides in FLP chemistry, presumably because the synthesis of these precursors requires phosphines as starting materials, which are already excellent partners to form FLPs. However, the carbogenic nature of ylides that allows the formation of $\mathrm{C}-\mathrm{C}$ bonds when organic substrates are activated and their intrinsic basicity that 


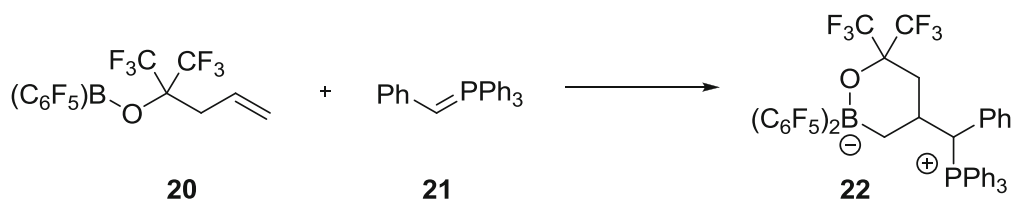

Scheme 8 Activation of alkenes employing ylides as bases

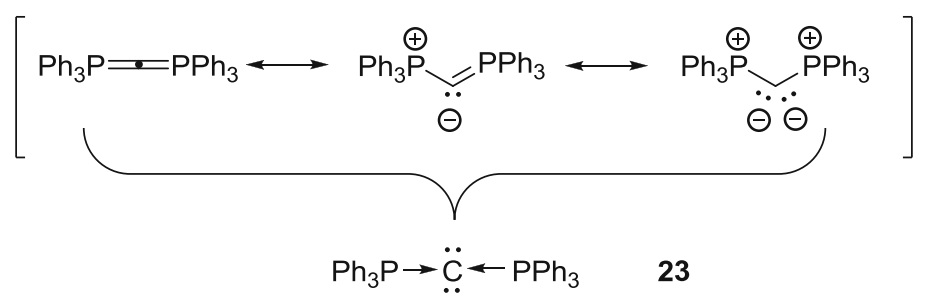

Scheme 9 Electronic distribution in carbodiphosphorane $\mathbf{2 3}$

clearly surpasses that depicted by phosphines may lead to the discovery of new applications.

In this regard Stephan has very recently demonstrated that tethered alkene-boranes $\mathbf{2 0}$ react efficiently with non-specially sterically encumbered Wittig ylides such as $\mathbf{2 1}$ with activation of the olefin and concomitant formation of a $\mathrm{C}-\mathrm{C}$ and a C-B bond (Scheme 8) [8].

Other phosphorus ylides have also been used as bases in this chemistry. Specifically, our research has been inspired by the theoretical papers of Frenking about the nature of carbodiphosphorane 23. They proposed that these bisylides should be considered to comprise two phosphines coordinated to a central carbon atom in zero oxidation state that retains its four valence electrons (Scheme 9 and Fig. 1) [9-12]. This view has been subsequently confirmed experimentally by the work of Bertrand, Fürstner, and others [13-16].

Due to this particular electronic distribution, compound 23 has to be an exceptionally good base. In fact, the calculated proton affinity of $\mathbf{2 3}$ surpasses the values reported for phosphines, amines and even NHCs [8]. In addition, the six phenyl groups sterically protect the central carbon atom against direct attack from Lewis acids rendering $\mathbf{2 3}$ as a very appropriate base for FLP chemistry.

The reactivity of the pair $23 / \mathrm{B}\left(\mathrm{C}_{6} \mathrm{~F}_{5}\right)_{3}$ toward organic substrates is summarized in Scheme 10 [17]. When 23 and $\mathrm{B}\left(\mathrm{C}_{6} \mathrm{~F}_{5}\right)_{3}$ were mixed in toluene at r.t., compound 24, deriving from the nucleophilic attack of the carbodiphosphorane at the para position of a pentafluorophenyl ring, was isolated. Interestingly, when the same reagents were mixed at $-78{ }^{\circ} \mathrm{C}$ this undesired reaction was not observed - instead an FLP was formed. At this temperature cleavage of molecular $\mathrm{H}_{2}$ occurs smoothly to form the phosphonium borohydride salt $\mathbf{2 5}$ in excellent yield. Under the same conditions the ring opening of ethers and lactones through $\mathrm{C}-\mathrm{O}$ bond cleavage to produce phosphonium borates $\mathbf{2 6}$ and $\mathbf{2 7}$ also took place.

As observed in the case of enamines, terminal alkynes such as phenylacetylene were activated via two possible ways, either involving deprotonation of the alkyne 

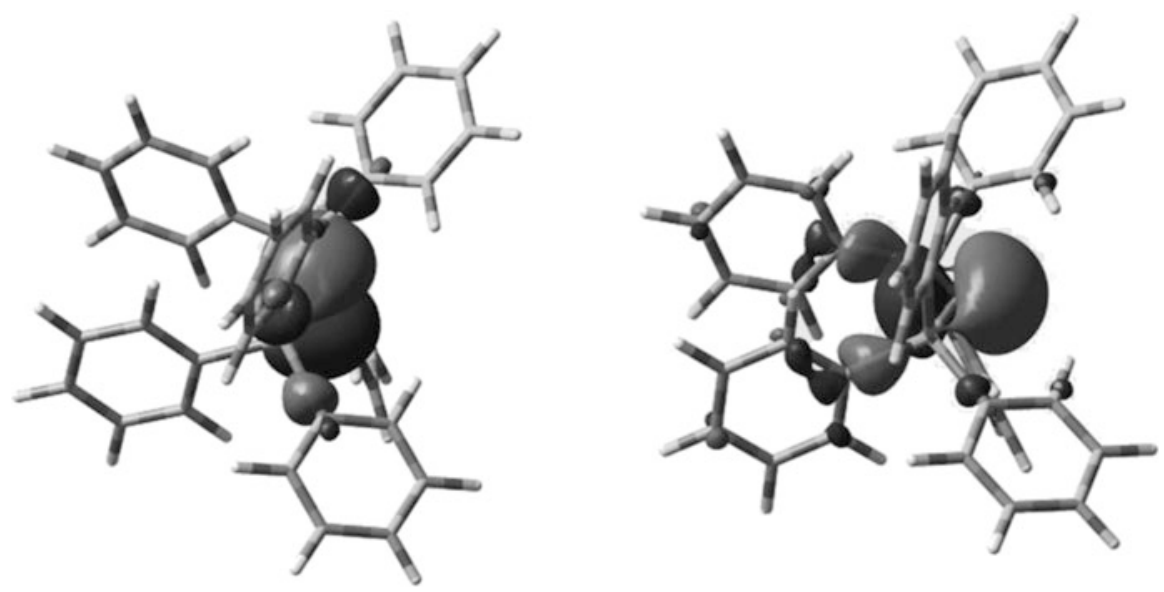

Fig. 1 Representation of the calculated Mono (left) and LUMO (Right) orbitals of $\mathbf{2 3}$<smiles>O=C(P)C(=P)c1c(F)c(F)c([B-](F)(F)C(F)(F)F)c(F)c1F</smiles>

24

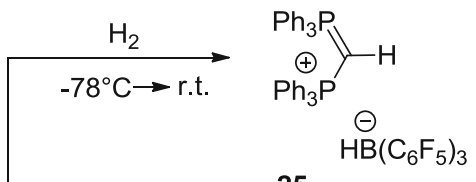

25

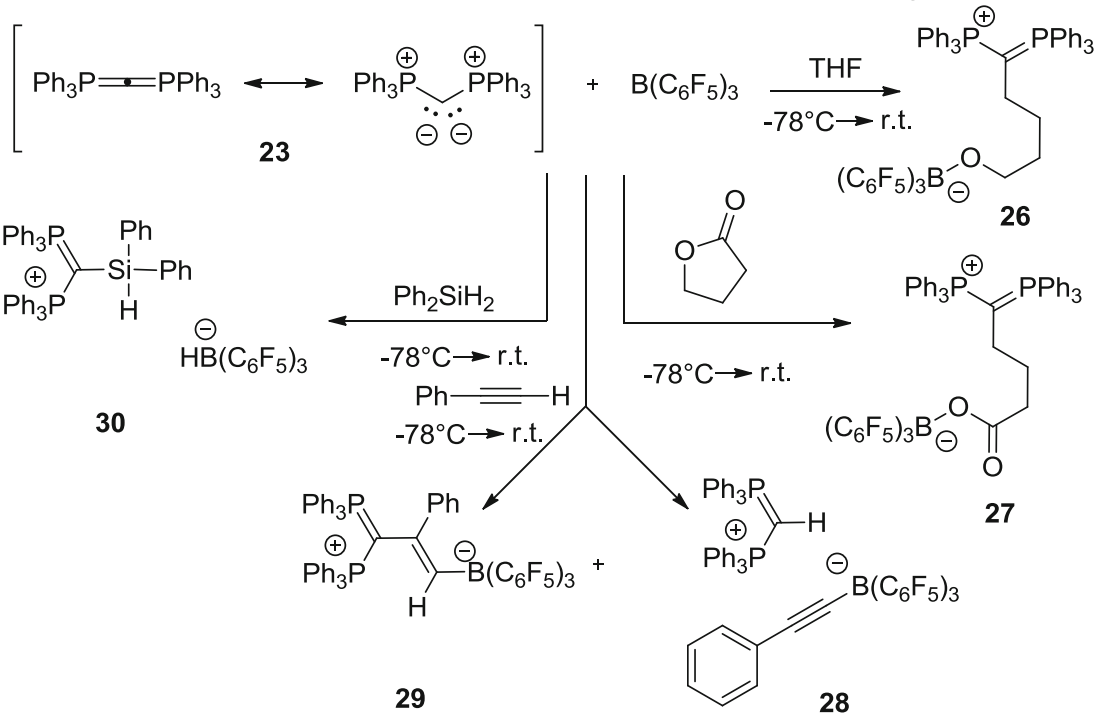

Scheme 10 Reactivity of the pair $23 / \mathrm{B}\left(\mathrm{C}_{6} \mathrm{~F}_{5}\right)_{3}$

forming salt $\mathbf{2 8}$ or by addition of the FLP to the $\mathrm{C}-\mathrm{C}$ triple bond of the alkyne affording zwitterion 29.

Activation of the $\mathrm{Si}-\mathrm{H}$ bond of silanes was also attempted [18-20]. Upon stirring equimolar mixtures of $\mathbf{2 3}, \mathrm{B}\left(\mathrm{C}_{6} \mathrm{~F}_{5}\right)_{3}$, and $\mathrm{Ph}_{2} \mathrm{SiH}_{2}$ the original yellow color of $\mathbf{2 3}$ 


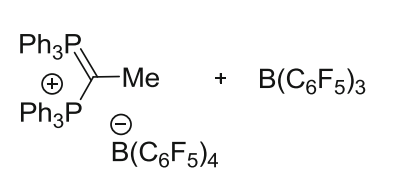

31

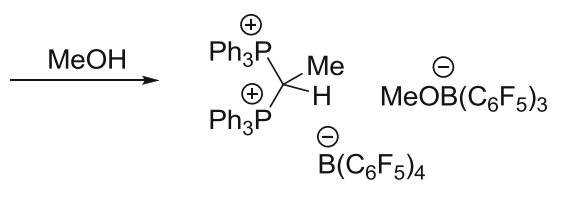

32

Scheme 11 Double frustration in carbodiphosphoranes

disappeared and the silylium borohydride $\mathbf{3 0}$ was isolated in pure form after column chromatography. In contrast, heterolytic cleavage of $\mathrm{Si}-\mathrm{F}$ and $\mathrm{Si}-\mathrm{O}$ bonds in $\mathrm{PhMe}_{2} \mathrm{SiF}$ and $\mathrm{Me}_{3} \mathrm{SiOPh}$ was not successful under the same reaction conditions.

The second proton affinity of $\mathbf{2 3}$ was estimated by Frenking in $-193.4 \mathrm{kcal} / \mathrm{mol}$ which gives an indication that even protonated or alkylated derivatives of $\mathbf{2 3}$ may further react as a frustrated Lewis pair in combination with $\mathrm{B}\left(\mathrm{C}_{6} \mathrm{~F}_{5}\right)_{3}$. To explore this possibility, the methylated salt 31 in combination with $\mathrm{B}\left(\mathrm{C}_{6} \mathrm{~F}_{5}\right)_{3}$ was employed in FLP chemistry. Although this pair was not able to activate $\mathrm{H}_{2}$ or $\mathrm{N}-\mathrm{H}$ of amines, it still cleaved the $\mathrm{O}-\mathrm{H}$ bond of methanol to produce 32 (Scheme 11). Even though in comparison with $23 / \mathrm{B}\left(\mathrm{C}_{6} \mathrm{~F}_{5}\right)_{3}$ the pair $31 / \mathrm{B}\left(\mathrm{C}_{6} \mathrm{~F}_{5}\right)_{3}$ has a considerably reduced degree of frustration, its formation is remarkable, especially if the cationic nature of the base $\mathbf{2 3}$ is considered.

\section{FLPs Constituted by Carbon-Based Acids}

The type of Lewis bases employed in FLP chemistry has expanded tremendously from the original phosphines to amines [21, 22], pyridines [23], or NHCs [24]. In sharp contrast the acid partner is basically limited to polyfluorinated boranes and in some special cases to polyfluorinated alanes [25]. In order to overcome this limitation several systems that employ carbon- and silicon-based Lewis acids have been attempted. However, it can be concluded that most of these Lewis acids are not competitive when compared with polyfluorinated boranes.

\subsection{Trityl Cations as Acids in FLP Chemistry}

Probably the most obvious carbon-based surrogate for $\mathrm{B}\left(\mathrm{C}_{6} \mathrm{~F}_{5}\right)_{3}$ is the isoelectronic trityl cation 33, a compound that shows quite strong Lewis acidity at the central carbon atom due to the simultaneous concurrence of an empty $\mathrm{p}$ orbital at that position and the global positive charge that the molecule bears. However, all attempts to form FLPs employing a trityl cation as the Lewis acid partner were unsuccessful owing to the strong tendency of this molecule to delocalize positive charge on the phenyl rings (Scheme 12a). This fact makes the sterically unprotected para positions to the central carbon atom prone to undergo nucleophilic aromatic 
a<smiles>c1ccc(C(c2ccccc2)c2ccccc2)cc1</smiles><smiles>C1=CCC(=C(c2ccccc2)c2ccccc2)C=C1</smiles><smiles></smiles>

b

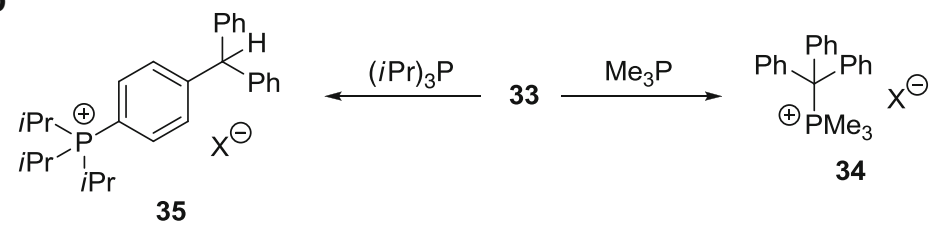

Scheme 12 (a) Resonace forms of trityl cation and (b) reactivity of $\mathbf{3 3}$ toward bases of different steric requirements

substitution in the presence of a nucleophile. As a result, if relatively small phosphines such as $\mathrm{Me}_{3} \mathrm{P}$ or $\mathrm{Ph}_{3} \mathrm{P}$ are used as the basic partner, the coordination of the phosphorus to the central carbon atom is observed (34). Conversely, the bulkier $(i \mathrm{Pr})_{3} \mathrm{P}$ does not react with the central carbon atom but it also does not lead to the formation of FLPs. Instead, a new adduct is formed in this case by the attack of the bulky phosphine on one of the para positions of the three phenyl rings in $\mathbf{3 5}$ (Scheme 12b) [26].

\subsection{Silylium Cations as Acids in FLP Chemistry}

Silyl cations can be classified as the heavier analogs of the trityl ones. However, the employment of silicon as the central atom introduces some beneficial factors that make them more suitable for FLP chemistry: (1) less efficient overlap between the $\mathrm{Si}(\mathrm{p})$ and the $\mathrm{C}(\mathrm{p})$ orbitals strongly localizes the LUMO on the Si centre and makes the nucleophilic attack at the aromatic substituents less favorable and (2) the longer $\mathrm{C}-\mathrm{Si}$ bond distance compared with $\mathrm{C}-\mathrm{C}$ permits the introduction of substituents at the ortho positions of the aromatic groups, introducing additional steric protection. Thus, in the presence of tris(mesityl)phosphine, the permethylated cation $\mathbf{3 6}$ forms an FLP which is able to activate $\mathrm{H}_{2}$ at atmospheric pressure producing silane $\mathbf{3 7}$ and the phosphonium salt 38 (Scheme 13) [27]. Whether these P/Si pairs are able to activate other organic substrates or not still needs further evaluation. 


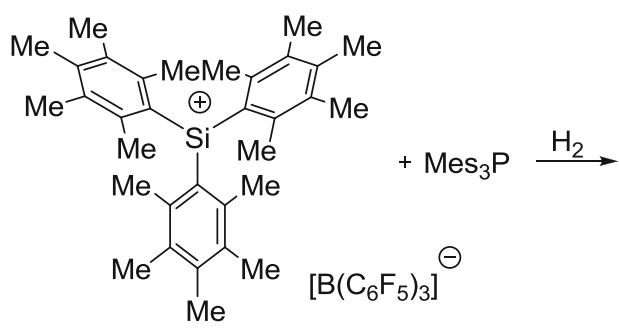

36

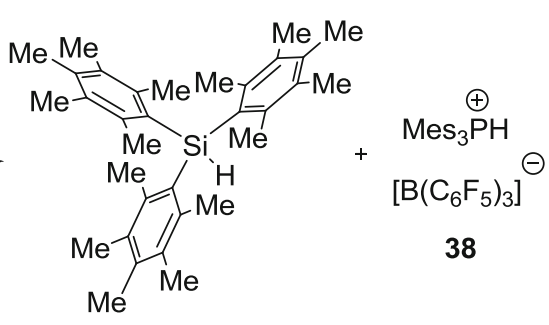

37

Scheme 13 Activation of $\mathrm{H}_{2}$ by a silyl cation/phosphine pair

\section{All Carbon-Based FLPs}

As described in Sect. 2, carbon-based Lewis bases are relatively frequent and easy available compounds; however, in order to design all carbon-based FLPs carbogenic Lewis acids are also necessary. Allene $\mathbf{3 9}$ has recently been proposed by our group as a convenient alternative to trityl cations in FLP chemistry. This compound exhibits an intrinsic charge separation originated by the tendency of the fluorene moieties to accept an electron pair in order to gain aromatization. Therefore, the central carbon atom has a partial carbocationic character while negative charge is delocalized at both termini of the allene. Since this electronic distribution does not delocalize positive charge on the aromatic substituents, the undesired nucleophilic attack by the base at these positions is avoided (Scheme 14) [28].

Combination of 39 with not very sterically demanding NHCs such as 1,3,4,5tetramethylimidazol-2-ylidene (40) and 1,3-di-tert-butylimidazol-2-ylidene (41) generated the classical adducts 42 and 43 respectively. In contrast, when 39 was mixed with 1,3-bis( $2^{\prime}, 6^{\prime}$-diisopropylphenyl)imidazol-2-ylidene (44), no interaction between the partners was detected by NMR spectroscopy indicating the formation of an FLP (Scheme 15).

By using Childs method the Lewis acidity of allene 39 has been quantified, showing it to be much weaker than in polyfluorinated boranes but still similar to that of $\mathrm{B}(\mathrm{OPh})_{3}$ [29]. Due to this limited acidity the activation of $\mathrm{H}_{2}$ was not possible; however, the weaker nonpolar covalent $\mathrm{S}-\mathrm{S}$ bond of disulfides was efficiently cleaved by the allene-NHC pair 39/44 affording the sulfide-sulfonium salt $\mathbf{4 5}$ (Scheme 16).

In an attempt to expand the scope of application of these carbon-based FLPs, other electron poor allenes were also tested as plausible acid partners. Thus, compounds 46-48 were synthesized and mixed with carbenes 41 and 44. At r.t. the allene-carbene adducts $\mathbf{4 9 - 5 2}$ were isolated and this adduct formation proved to be irreversible. More interestingly, at $-78^{\circ} \mathrm{C}$ no such adducts were detected and at this temperature the allene-carbene mixtures were again able to activate the $\mathrm{S}-\mathrm{S}$ bond of disulfides (Scheme 17) [30]. 


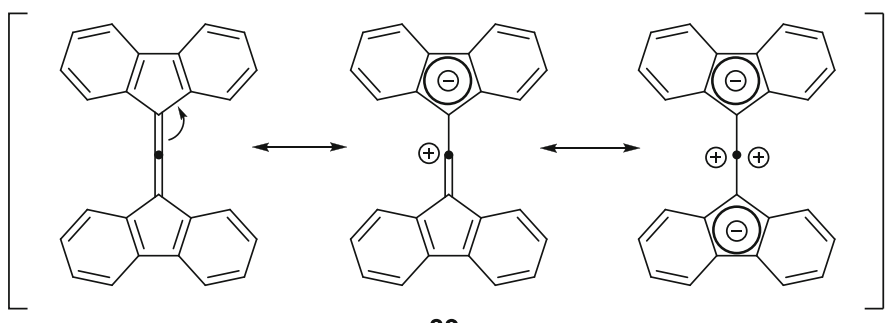

39

Scheme 14 Resonance structures of allene 39

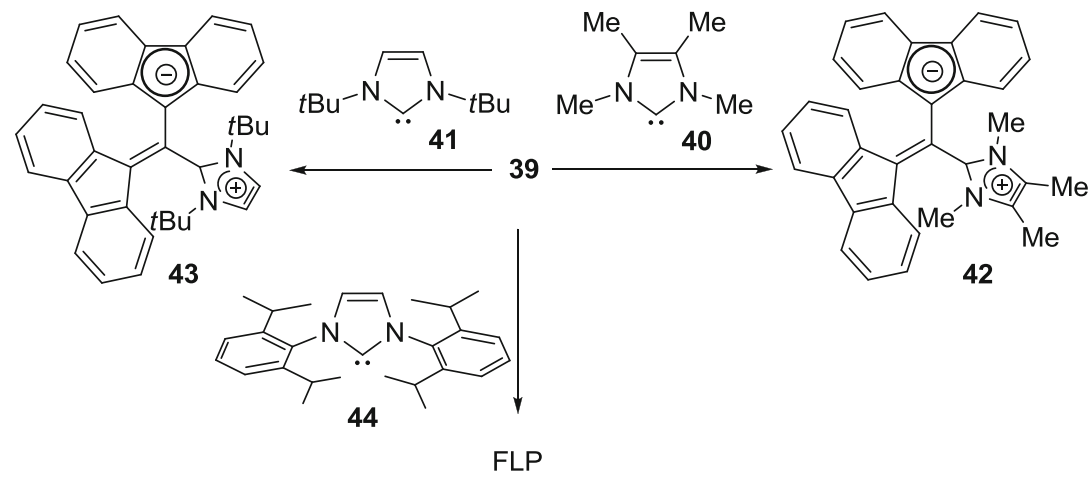

Scheme 15 Reactivity of allene 39 towards NHCs

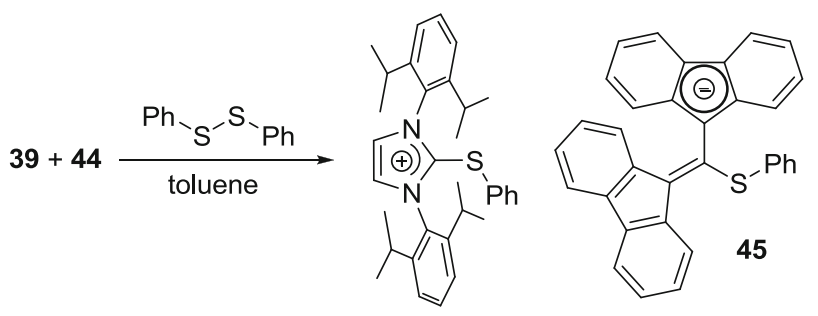

Scheme 16 Activation of S-S bond in disulfides by completely carbogenic FLPs

Intermediate situations between adduct formation and frustrated reactivity have been previously described. For example, the mixture of 2,6-lutidine and $\mathrm{B}\left(\mathrm{C}_{6} \mathrm{~F}_{5}\right)_{3}$ affords the corresponding Lewis adduct at $-10{ }^{\circ} \mathrm{C}$ while at r.t. an equilibrium is established [31]. This scenario in which thermal activation is required to reach frustration has been named "thermally induced frustration." However, in the case of these allenes, low temperature is required to preserve FLP reactivity and avoid the irreversible quenching of the partners. Therefore it can be concluded that in these systems the observed frustration has a kinetic nature. Further studies with other allenes are still needed in order to ascertain whether the activation of other substrates apart from disulfides can be achieved (Fig. 1). 
<smiles>CCOC(=O)C(=C=C(C(=O)OCC)C(=O)OCC)C(=O)OCC</smiles>

46

41<smiles></smiles>

$E=$ COOEt<smiles>CCOC(=O)C(=C=C1c2ccccc2-c2ccccc21)C(=O)OCC</smiles>

41 or 44

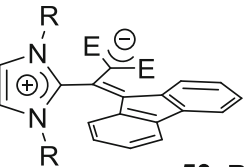

50; $\mathrm{R}=t \mathrm{Bu}$

51; $\mathrm{R}=$ Diip<smiles>CCOC(=O)C(=C=C1c2ccc(F)cc2-c2cc(F)ccc21)C(=O)OCC</smiles>

41

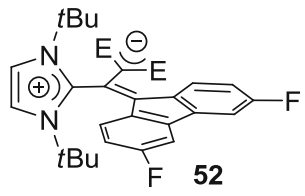

Scheme 17 Carbene-allene adducts formation

\section{Conclusions}

In conclusion, the results described here demonstrate that pure hydrocarbons such as allenes can be used as Lewis acids in the framework of FLP chemistry. Even though the grade of "frustration" obtained up to now by combinations of electron deficient allenes with a bulky NHC is lower than in the cases of some well established B/P pairs, it can be envisaged that modifications, such as the introduction of electron-withdrawing groups on their structures might increase their Lewis acidity to the level necessary for the activation of a wider range of molecules. Therefore future work can be expected in order to explore the potential of these systems in areas such as organocatalysis.

\section{References}

1. Blackwell JM, Piers WR, Parvaez M, McDonald R (2002) Solution and solid state characteristics of imine adducts with tris(pentafluorophenyl)borane. Organometallics 21:1400-1407. doi:10.1021/om011086n

2. Döring S, Erker G, Fröhlich R, Meyer O, Bergander K (1988) Reaction of the Lewis acid tris (pentafluorophenyl)borane with a phosphorus ylide: competition between adduct formation and electrophilic and nucleophilic aromatic substitution pathways. Organometallics 17:2183-2187. doi:10.1021/om9709953

3. Spies P, Schwendemann S, Lange S, Kehr G, Fröhlich R, Erker G (2008) Metal-free catalytic hydrogenation of enamines, imines, and conjugated phosphinoalkenylboranes. Angew Chem Int Ed 47:7543-7546. doi:10.1002/anie.200801432 
4. Dureen MA, Brown CC, Stephan DW (2010) Addition of enamines or pyrroles and $B\left(\mathrm{C}_{6} \mathrm{~F}_{5}\right)_{3}$ "frustrated Lewis pairs" to alkynes. Organometallics 29:6422-6432. doi:10.1021/om1008346

5. Pelter A, Smith K, Brown HC (1988) Borane reagents. Academic, London

6. Aggarwal VK, Fang GY, Ginesta X, Howells DM, Zaja M (2006) Toward an understanding of the factors responsible for the 1,2-migration of alkyl groups in borate complexes. Pure Appl Chem 78:215-229. doi:10.1351/pac200678020215

7. Bao-Hua X, Kehr G, Frohlich R, Erker G (2011) 6-Dimethylaminopentafulvene as a Lewis base component in frustrated Lewis pairs: reversible carbon-carbon coupling in FLP chemistry. Organometallics 30:5080-5083. doi:10.1021/om200818x

8. Zhao W, Stephan DW (2012) Frustrated Lewis pair olefin addition reactions: P-, N-, C- and Hbased nucleophilic additions to an olefin-tethered borane. Chem Sci 3:2123-2132. doi: $10.1039 / \mathrm{c} 2 \mathrm{sc} 20262 \mathrm{j}$

9. Tonner R, Frenking G (2008) Divalent carbon(0) chemistry, part 1: parent compounds. Chem Eur J 14:3260-3272. doi:10.1002/chem.200701390

10. Tonner R, Frenking G (2008) Divalent carbon(0) chemistry, part 2: protonation and complexes with main group and transition metal Lewis acids. Chem Eur J 14:3273-3289. doi:10.1002/ chem. 200701392

11. Tonner R, Frenking G (2007) $\mathrm{C}(\mathrm{NHC})_{2}$ : divalent carbon(0) compounds with $\mathrm{N}$-heterocyclic carbine ligands-theoretical evidence for a class of molecules with promising chemical properties. Angew Chem Int Ed 46:8695-8698. doi:10.1002/anie.200701632

12. Tonner R, Öxler F, Neumüller B, Petz W, Frenking G (2006) Carbodiphosphoranes: the chemistry of divelent carbon(0). Angew Chem Int Ed 45:8038-8042. doi:10.1002/ anie. 200602552

13. Dyker CA, Lavallo V, Donnadieu B, Bertrand G (2008) Synthesis of an extremely bent acyclic allene (a "carbodicarbene"): a strong donor ligand. Angew Chem Int Ed 47:3206-3209. doi:10.1002/anie.200705620

14. Alcarazo M, Lehmann CW, Anoop A, Thiel W, Fürstner A (2009) Coordination chemistry at carbon. Nat Chem 1:295-301. doi:10.1038/nchem.248

15. Dyker CA, Bertrand G (2009) Chemical bonding: rethinking carbon. Nat Chem 1:265-266. doi:10.1038/nchem.265

16. Melaimi M, Parameswaran P, Donnadieu B, Frenking G, Bertrand G (2009) Synthesis and ligand properties of a persistent, all-carbon four-membered-ring allene. Angew Chem Int Ed 48:4792-4795. doi:10.1002/anie.200901117

17. Alcarazo M, Gomez C, Holle S, Goddard R (2010) Exploring the reactivity of carbon(0)/ borane-based frustrated Lewis pairs. Angew Chem Int Ed 49:5788-5791. doi:10.1002/ anie. 201002119

18. Parks DJ, Piers WE (1996) Tris(pentafluorophenyl)boron - catalyzed hydrosilation of aromatic aldehydes, ketones and esters. J Am Chem Soc 118:9440-9441. doi:10.1021/ja961536g

19. Parks DJ, Blackwell JM, Piers WE (2000) Studies on the mechanism of $B\left(\mathrm{C}_{6} \mathrm{~F}_{5}\right)_{3}$-catalyzed hydrosilation of carbonyl functions. J Org Chem 65:3090-3098. doi:10.1021/jo991828a

20. Blackwell JM, Morrison DJ, Piers WE (2002) B( $\left.\mathrm{C}_{6} \mathrm{~F}_{5}\right)_{3}$-catalyzed hydrosilation of enones and silyl enol ethers. Tetrahedron 58:8247-8254. doi:10.1016/S0040-4020(02)00974-2

21. Sumerin V, Schulz F, Nieger M, Leskelä M, Repo T, Rieger B (2008) Facile heterolytic $\mathrm{H}_{2}$ activation by amines and $\mathrm{B}\left(\mathrm{C}_{6} \mathrm{~F}_{5}\right)_{3}$. Angew Chem Int Ed 47:6001-6003. doi:10.1002/ anie. 200800935

22. Chase $P$, Jurka T, Stephan DW (2008) Lewis acid-catalyzed hydrogenation: $B\left(\mathrm{C}_{6} \mathrm{~F}_{5}\right)_{3}$ mediated reduction of imines and nitriles with $\mathrm{H}_{2}$. Chem Commun 1701-1703. doi:10.1039/ b718598g

23. Geier SJ, Gille AL, Gilgert TM, Stephan DW (2009) From classical adducts to frustrated Lewis pairs: steric effects in the interactions of pyridines and $B\left(C_{6} F_{5}\right)_{3}$. Inorg Chem 48:10466-10474. doi:10.1021/ic901726b 
24. Holschumacher D, Bannenberg T, Hrib CG, Jones PG, Tamm M (2008) Heterolytic dihydrogen activation by a frustrated carbene-borane Lewis pair. Angew Chem Int Ed 47:7428-7432. doi:10.1002/anie.200802705

25. Dureen MA, Stephan DW (2009) Terminal alkyne activation by frustrated and classical Lewis acid/phosphine pairs. J Am Chem Soc 131:8396-8397. doi:10.1021/ja903650w

26. Cabrera L, Welch GC, Masuda JD, Wie P, Stephan DW (2006) Pyridine and phosphines reactions with $\left[\mathrm{CPh}_{3}\right]\left[\mathrm{B}\left(\mathrm{C}_{6} \mathrm{~F}_{5}\right)_{4}\right]$. Inorg Chim Acta 359:3066-3071. doi:10.1016/j.ica.2006.02.006

27. Schäfer A, Reißmann M, Schäfer A, Saak W, Haase D, Müller T (2011) A new synthesis of triarylsilylium ions and their application in dihydrogen activation. Angew Chem Int Ed 50:12636-12638. doi:10.1002/anie.201106582

28. Inés B, Holle S, Goddard R, Alcarazo M (2010) Heterolytic S-S bond cleavage by a purely carbogenic frustrated Lewis pair. Angew Chem Int Ed 49:8389-8391. doi:10.1002/ anie. 201004149

29. Britovsek GJP, Ugotti U, White AJP (2005) From $\mathrm{B}\left(\mathrm{C}_{6} \mathrm{~F}_{5}\right)_{3}$ to $\mathrm{B}\left(\mathrm{OC}_{6} \mathrm{~F}_{5}\right)_{3}$ : synthesis of $\left(\mathrm{C}_{6} \mathrm{~F}_{5}\right)_{2} \mathrm{BOC}_{6} \mathrm{~F}_{5}$ and $\left(\mathrm{C}_{6} \mathrm{~F}_{5}\right) \mathrm{B}\left(\mathrm{OC}_{6} \mathrm{~F}_{5}\right)_{2}$ and their relative Lewis acidity. Organometallics 24:1685-1691. doi:10.1021/om049091p

30. Palomas D, Holle S, Inés B, Bruns H, Goddard R, Alcarazo M (2012) Synthesis and reactivity of electron poor allenes: formation of completely organic frustrated Lewis pairs. Dalton Trans 41:9073-9082. doi:10.1039/C2DT30195D

31. Geier SJ, Stephan DW (2009) Lutidine/B $\left(\mathrm{C}_{6} \mathrm{~F}_{5}\right)_{3}$ : at the boundary of classical and frustrated Lewis pair reactivity. J Am Chem Soc 131:3476-3477. doi:10.1021/ja900572x 